\title{
Stereotactic Biopsy in The Diagnosis of Small Brain Lesion
}

\author{
S DAS ${ }^{\mathrm{a}}, \mathrm{MS}^{\mathrm{BHUIYAN}}{ }^{\mathrm{b}}, \mathrm{D} \mathrm{GHOSH}^{\mathrm{c}}, \mathrm{MM}^{\mathrm{RASHID}}{ }^{\mathrm{d}}$
}

\begin{abstract}
:
Background: Stereotactic neurosurgery involves mapping the brain in a three-dimensional coordinate system. With the help of MRI and CT scans and 3D computer workstations, neurosurgeons are able to accurately target any area of the brain especially deep seated and brain stem.

Objectives: Stereotactic brain biopsy is a minimally invasive procedure that uses this technology to obtain samples of brain tissue for diagnostic purpose of multiple brain disorder where start to any medication was impossible or no response to any medical management for long term.
\end{abstract}

\section{Introduction:}

Stereotaxy (from stereo meaning "solidity", and tactile meaning "touch") refers to any technique that involves the recording and reproduction of three-dimensional haptic information or creating an allusion of depth to the sense of touch within an otherwise-flat surface. Stereotactic biopsy allows neurosurgeons to localize and sample intrinsic lesions located anywhere within the brain accurately.

Stereotactic neurosurgery has a long history. Sir Victor Horsely and Clarke first described stereotactic

a) Dr. Sukriti Das, AssociateProfessor, Department of Neurosurgery, Dhaka Medical College \& Hospital, Dhaka.

b) Dr. Md. Sharif Bhuiyan, Phase-B Resident, Department of Neurosurgery, Dhaka Medical College \& Hospital, Dhaka.

c) Dr. Dipankar Ghosh, Phase-B Resident, Department of Neurosurgery, Dhaka Medical College \& Hospital, Dhaka.

d) Dr. Md. Mamunur Rashid, Phase-B Resident, Department of Neurosurgery, Dhaka Medical College \& Hospital, Dhaka.

Adddress of Correspondence: Dr. Sukriti Das, FCPS, MS, FRCS (Edin.), Associate Professor, Department of Neurosurgery, Dhaka Medical College \& Hospital, Dhaka, Bangladesh. Cell phone: +8801711676848, e-mail: sukriti66@yahoo.com
Materials and Methods: Twenty-five patients underwent stereotactic biopsy of brain lesions using “КОМАI" Stereotactic frame system and were enrolled.

Results: Of the 25 cases, positive tissue biopsy was found in 20 cases. In 5 patients, biopsy showed gliotic brain tissue or normal brain tissue. There was no post-operative new deficits or mortality seen.

Conclusion: Stereotaxy is minimally invasive procedure having no complication. So, before starting any medication blindly stereotactic tissue diagnosis can help a lot in many medical and surgical diseases.

(J Bangladesh Coll Phys Surg 2021; 39: 24-35)

DOI: https://doi.org/10.3329/jbcps.v39i1.50453

frame in 1908. The main purpose of this frame was to treat patients for delivery of radiation, surgical targeting of electrodes, epilepsy, vascular malformations, and pain syndromes.

Interest in the development of stereotactic surgery in humans has been documented in the literature as early as the 19th century ${ }^{1,2,3}$. The first stereotactic device used in humans was used by Martin Kirschner, for a method to treat trigeminal neuralgia by inserting an electrode into the trigeminal nerve and ablating it. He published this in $1933^{4,5,6,7}$.

In 1936, Hirotaro Narabayashi was also developing a frame adapted from the original Horsley and Clarke orthogonal design in Japan ${ }^{8}$. However, because of Japan's limited exposure to the rest of the world after the war, he was completely unaware of the concurrent work in the US, France, Germany, and Sweden ${ }^{9}$. In response to Narabayashi's publication "Procain oil blocking of the globus pallidus in $1956 " 10$. Spiegel and Wycis wrote, "In this way they try to create the impression that they were the first who performed stereotactic operations on the basal 
ganglia, not even mentioning with a single word the fact that we have reported such operations repeatedly since 1949". The art of "sharpshooting into the brain" continued to be advanced through the efforts of multiple neurosurgeons and scientists worldwide including Hecaen et $\mathrm{al}^{11,12,13,14}$.

With the advent of computed tomography (CT) in the 1970 s came the ability to precisely visualize the location of lesions affecting the central nervous system (CNS). Initially, CT- guided freehand techniques were used to obtain tissue from intracranial lesions until rigidly fixed stereotactic head frames were developed in the early $1980 \mathrm{~s}^{15}$.

After advent of CT \& MRI various frames are designed, like Leksell frame, CRW frame and more which uses A stereotactic planning system, including atlas, multimodality image matching tools, coordinates calculator, etc. Modern stereotactic planning systems are computer based. The stereotactic atlas is a series of cross sections of anatomical structure (for example, a human brain), depicted in reference to a two-coordinate frame. Thus, each brain structure can be easily assigned a range of three coordinate numbers, which will be used for positioning the stereotactic device. In most atlases, the three dimensions are: latero-lateral (x), dorso-ventral (y) and rostro-caudal (z). Planning station can fuse the CT and MRI images to precisely target the lesion. Frameless Stereotaxy like Neuronavigation also has a great role in taking brain tumor biopsies and other procedures.

This procedure is indicated when the pathology of the target is unknown or when future therapy will be influenced by the histologic nature of the lesion. Another indication for the use of this form of surgery is the medically fragile patient in whom a general anesthetic carries substantial risk. Stereotactic sampling is appropriate for lesions that are located deep within the brain, ineloquent cortex, are surgically unresectable and diffusely infiltrating, or are cystic and causing significant mass effect on surrounding neural structures, in which case aspiration may result in decompression of CNS tissue and restoration of function. Stereotactic technique also is useful for determining the etiology of multiple intracranial lesions or when cytoreductive surgery would not benefit the patient ${ }^{16}$.

\section{Material and Methods:}

Place of study: Dhaka medical college hospital Study population (Sample size): Total 25 patients were enrolled.

Ethical issue: All cases were done prior permission of the patient or patient party.

Data were collected prospectively.

All our procedures were done by using "KOMAI" frame of Japanese origin.

- Introduction to the Frame system-

- SurgicalTechnique-

Frame fixation: The frame and all it sattach mentsare sterilize dexcept the gauge plates. Patient is brought to operation theater or procedure room. A broad-spectrum antibiotic injection is given. Head is preferably shaved. If the patient is alert, he is placed on wheel chair or if not so alert he is placed on a patient trolley. Ananalgesic injection or suppository is given one hour prior to bring the patient for frame fixation. A scalp block is the given. Local anesthetic agents are injected over the scalp down to pericranium at four point of screw insertion. Then the frame is held horizontally without tilt and four screws are fixed and then the patient is taken to CT scan room to get a CT scan. The gauge plates are attached on both sides to get the " $Z$ " axis measurement. The scan should include the whole frame (Figure 3). Grid is placed, Target selected. Target for biopsy is measured (Figure 4). Target for biopsy is measured manually in the CT scan monitor along the $\mathrm{X}, \mathrm{Y}, \mathrm{Z}$ axis (Fig-4). At first a horizontal and a vertical line drawn at middle of brain which were directed by frame. Then lesion measured from that two line in $\mathrm{X}$-axis and $\mathrm{Y}$-axis accordingly. Z-axis measurement taken from point created by twogauge plates of the frame.

$>\quad$ The Biopsy procedure: The patient is then taken to the operating room. Placed on the 
operating table head frame is placed on the Acrylic frame, an " $\mathrm{L}$ "burr is fixed to make the patient's face free to breath and observation. An IV line is established and Normal saline started. Pulse oximeter and a BP cuff is fixed to monitor Oxygen saturation, pulse rate and Periodic BP. Then properly draped with sterile towels. Now the patient's head is properly cleaned, painted and draped. The $\mathrm{X}, \mathrm{Y}$ and $\mathrm{Z}$ attachments are fixed according to the measurement taken from CT scan.A safe trajectory is chosen. A burr hole is done after injecting Local anesthetics then the Biopsy cannula adaptor is fixed on the arc. The biopsy cannula is inserted slowly up to the mark given on the cannula. The biopsy cannula is a double-barreled hollow (including the trocar) cannulas. There are two slit opening in each cannula. There is a mark on the top of the cannula that indicate when the both slit openings are in the same place. At this point with a 10-cc syringe a small vacuum pressure is applied so that some tumor tissue enters in to the biopsytube. Then immediately the inner cannula is rotated to any side, the tissue inside is cut and the inner cannula is taken out and we can get a piece of tiny tissue. Three or four samples are taken in the same way from different sides by rotating the main cannula(Figure $5 \& 6$ ). Then the cannula is withdrawn slowly. All the attachments are removed. The burr hole site is, repaired in two layers a dressing is given. Patient is the sent to his bed. Close follow up for 24 hours is done then sent back home on the next day.

\section{SelectionCriteria:}

I. An undiagnosed intra-axial mass lesion that could not be approved by standard craniotomy without undue risk ofmorbidity.

II. Invasive lesions without significant masseffect.

III. Poorly defined lesions on CT orMRI.

IV. An intracranial lesion in a patient whose general medical status precluded craniotomy.

V. A condition for which medical therapy would likely be superior to operative resection (e.g., multiple lesions).

VI. Differentiating between tumor recurrence and radionecrosis

VII. Suspicion of lesions with significant radio-sensitivity such as lymphomas and germinoma.

VIII. Lesions which are highly susceptible to non-neoplastic origin such as infections and demyelinating lesions.

IX. Patients with poor general medical conditions who could not tolerate general anesthesia and major surgery.

\section{Results:}

There were 20 male and 5 female patients and the ratio is 4:1 (figure 7). Theage of patients was ranged from 30-75 years and mean age was 52.5 years. Most prevalent age period of disease wasthe fifth decade.

Majority of the patient presented with headache and vomiting. Visual problem was also found to be a significant presentation (Table-1).

According to accessibility to imaging tools and facilities, the patients underwent CT scan or MRI. Majority of the patient diagnosed as the main diagnosis before stereotactic biopsy were glioblastoma multiforme, metastasis and tuberculosis (Table- 2).

Figure 8 shows, out of total 25 study populations multiple lesions were found in 17 cases detected either in head CT or MRI of brain. Rest of the cases had single lesion.

Furthermore, in some cases for the better judgment of lesions both methods were used. Multiple brain lesions were considered as two or more discrete lesions in multiple cerebral lobes, multiloculated lesions in multiple lobes and diffuse involvement of brain in multiple lobes as seen in glioma. Eight patients had single deep-seated lesion and seventeen had multiple lesions in both hemispheres. All of the 
stereotactic biopsies were conducted using KOMAI head frame system and all of the samples were taken using biopsy needle and aspiration.

We have operated 25 cases for deep seated brain tumor biopsies by using our frame system. In 20 cases we could take out proper target tissue. There was no significant postoperative complication or morbidity found. No case of mortality was found. Histological diagnosis of lesions is summarized in Table-3.

Of all patients, 8 of the patients had gliomas, among them 2 pilocytic astrocytoma were multifocal and 3 were glioblastoma multiforme (Figure 9).

One of the patients had multiple small lesions and diagnosed as neurocysticercosis (Fig-10). In this case microscopic finding reveals scolex of cysticercus cellulosae containing rostellum and sucker. It also shows infiltration of chronic inflammatory cells including lymphocytes, macrophages and plasma cellssurrounding the parasite. It also reveals formation of granuloma containing plenty of giant cells and epithelioids. Some of the area shows gliosis, fibrosis and edema.

Out of 8 gliomas, more than half cases had low grade multifocal gliomas, and majority of them were distributed lesions that involved adjacent lobes. Numerous points of them had undergone enhancement so appeared as numerous multifocal lesions. Furthermore, one case was Non- Hodgkin lymphoma (figure 11), which have not responded to pre-operative corticosteroid. Three patients had metastatic tumor (figure 12), which were multiple and did not have anysymptoms of primary tumor in any other part of their bodies prior to the biopsy. Another 2 patients had multiple brain abscesses (Figure 13) with whom the intra abscess pus drainage was conducted beside the biopsy of abscess wall in order to help improvement of patients' clinical and neurological condition and these patients subsequently treated with antimicrobial therapy.

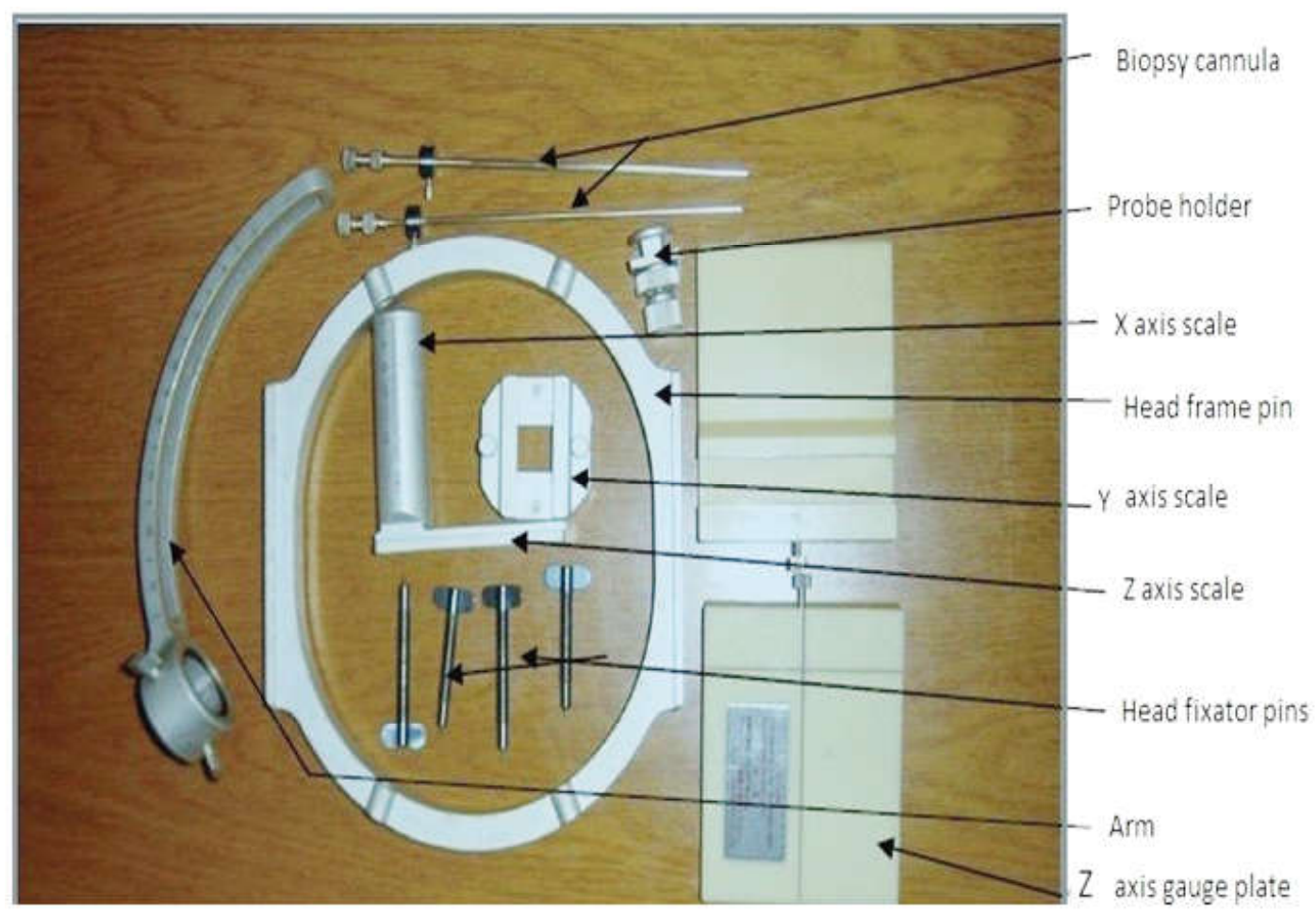

Fig 1: Parts of KOMAI headframesystem 


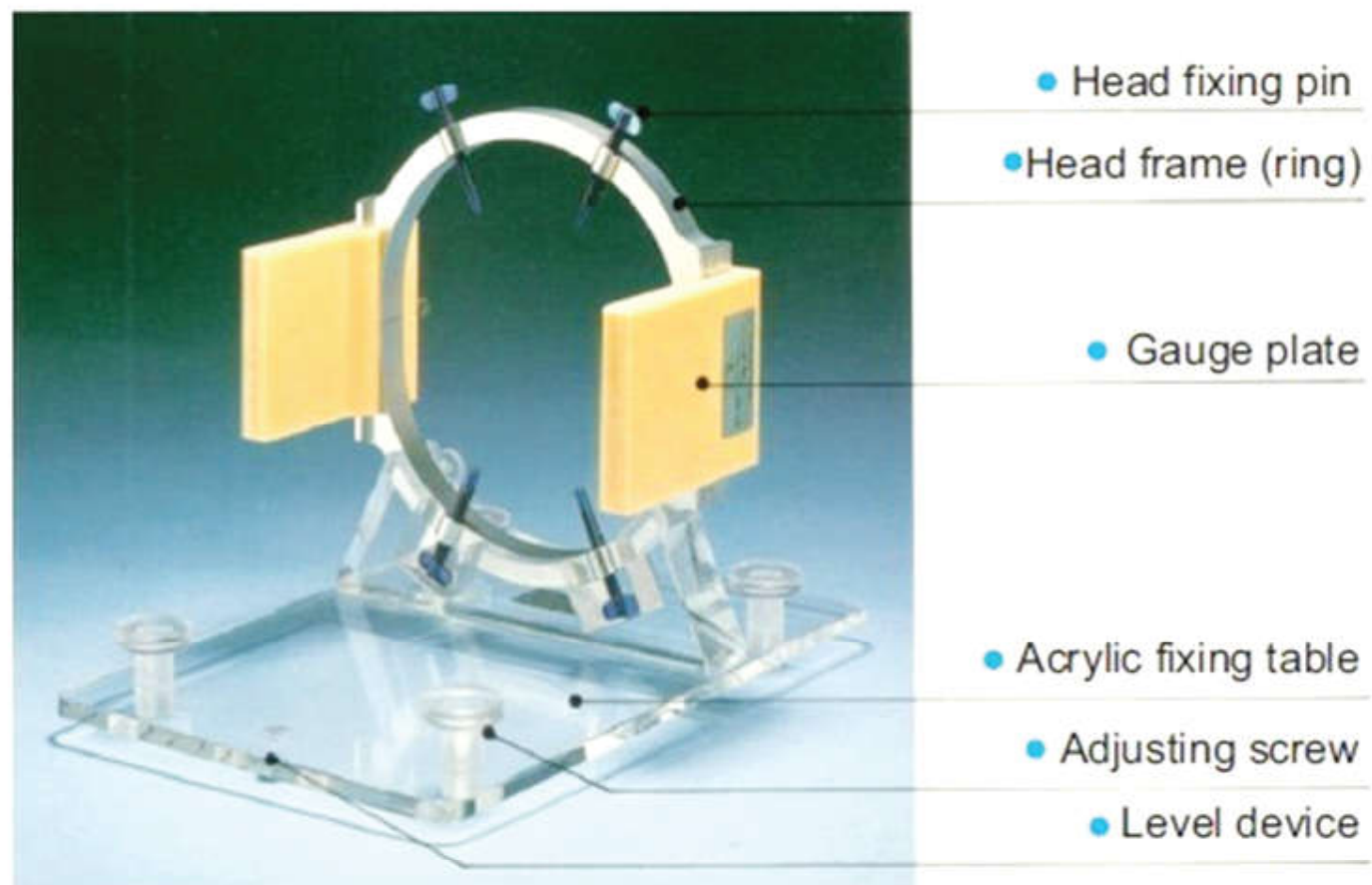

Fig 2: Basic setting for KOMAI head frame system
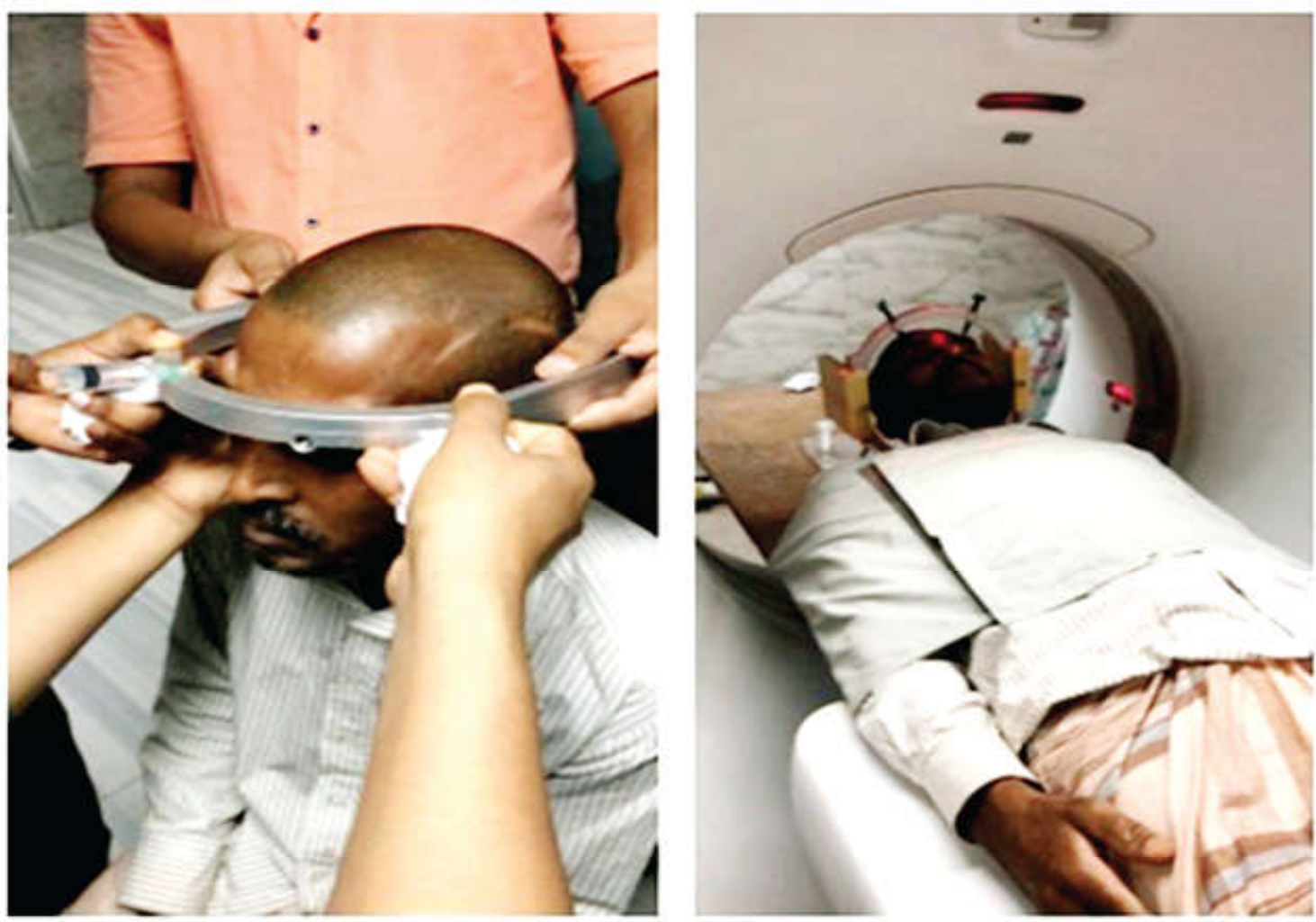

Figure 3: Framing and within CT scan room with frame 


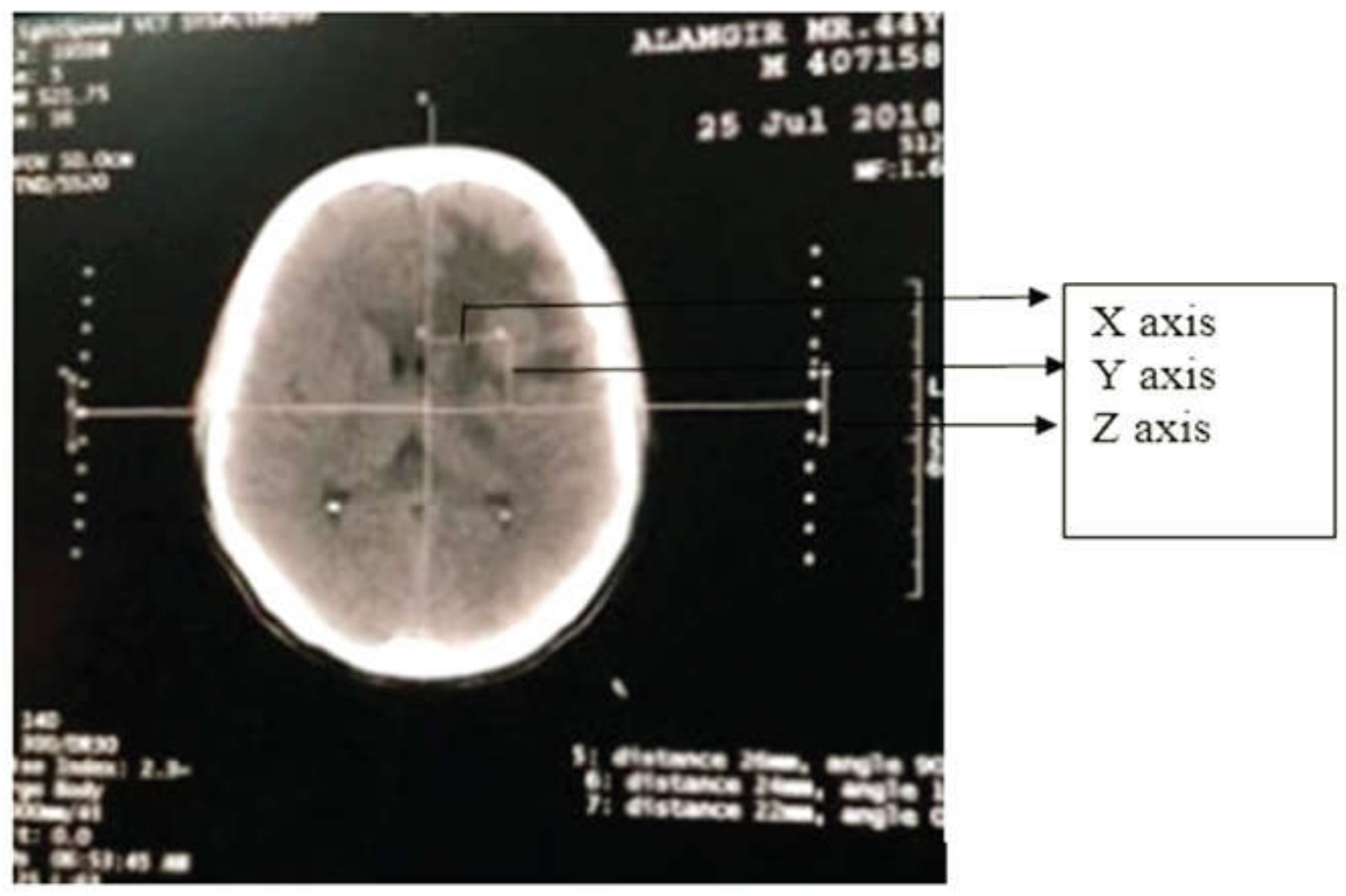

Figure 4: $\mathrm{X}, \mathrm{Y}, \mathrm{Z}$ axis in $\mathrm{CT}$ film
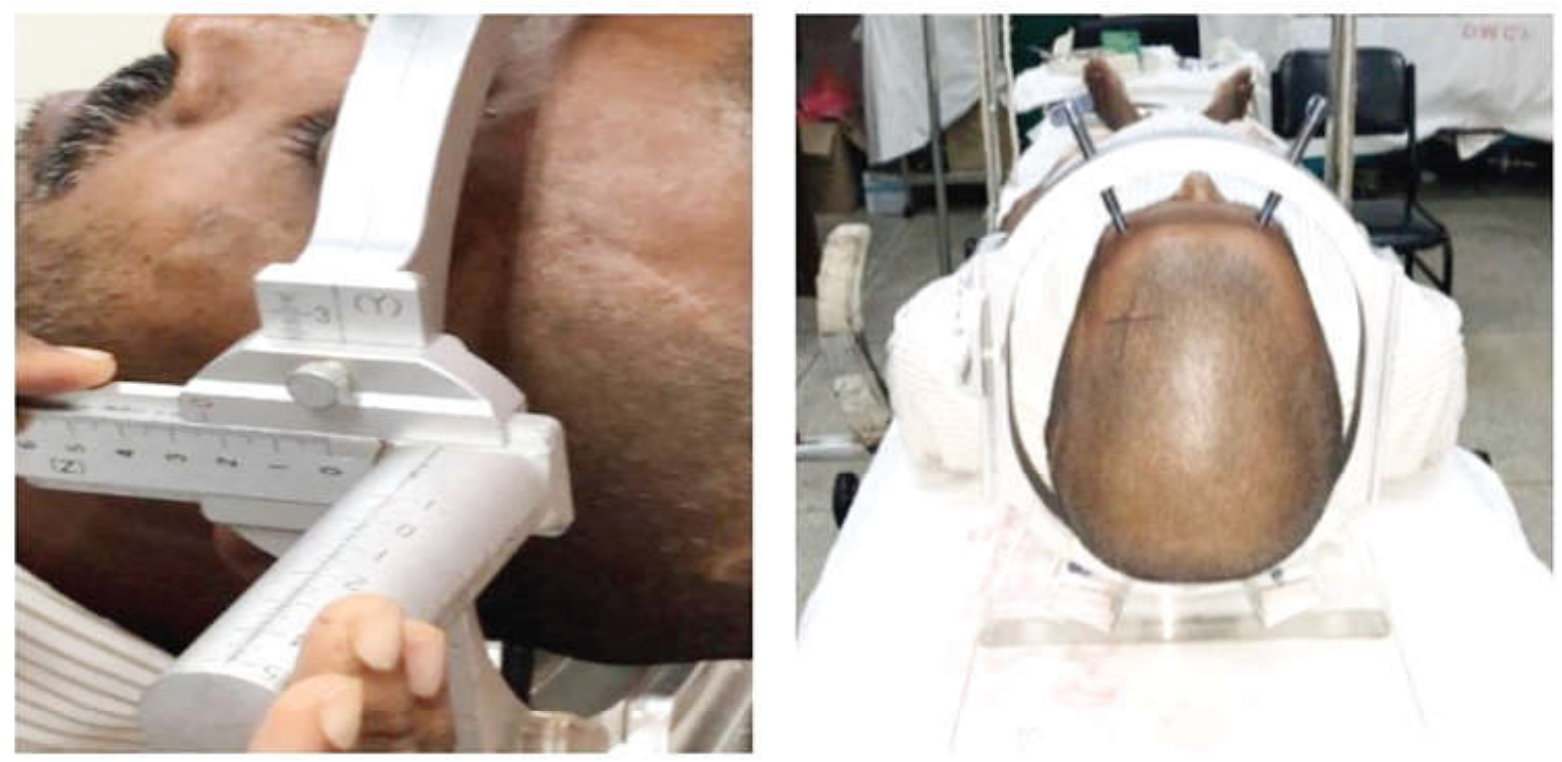

Figure 5: X, Y, Z targeted in scalp 

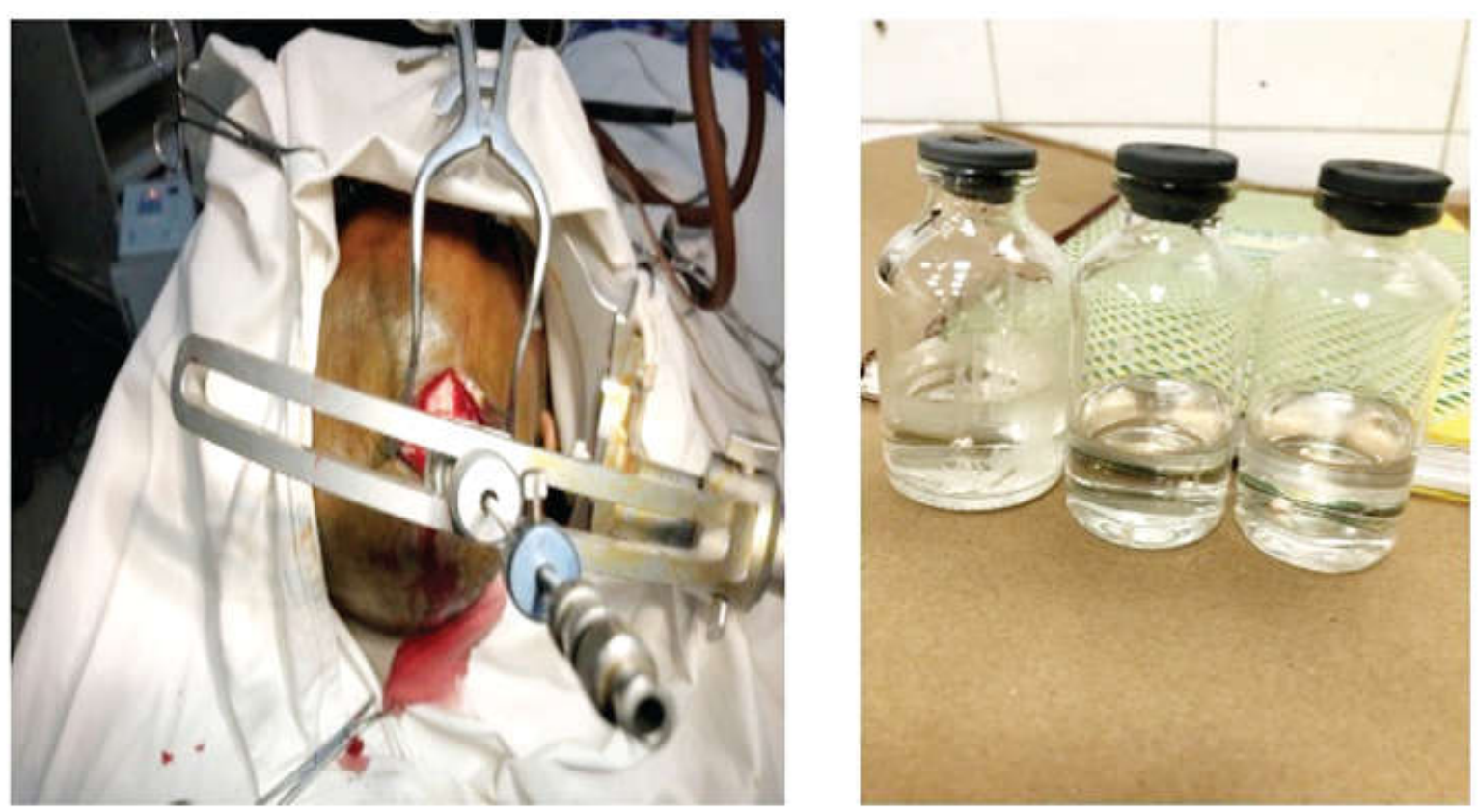

Figure 6: Specimen collection and ready for biopsy

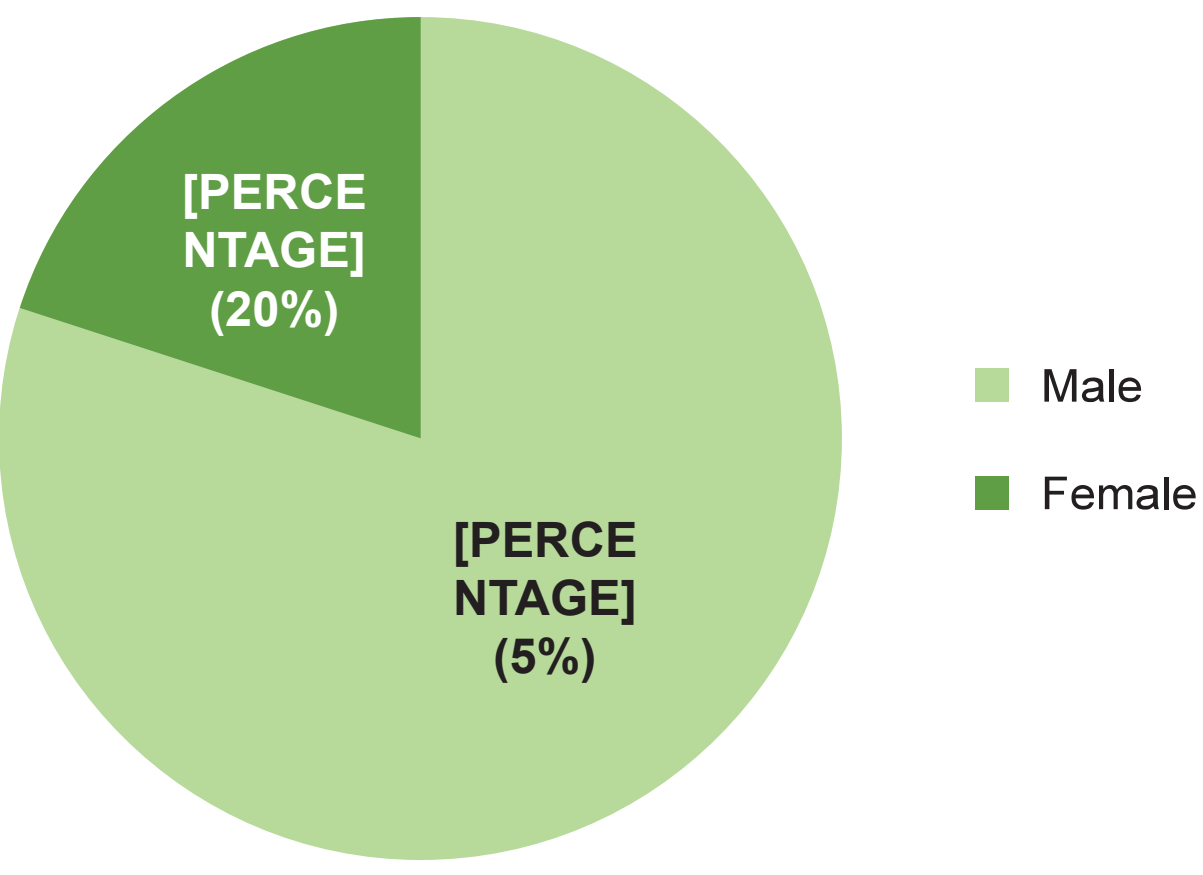

Figure 7: Case distribution (Gender wise) 


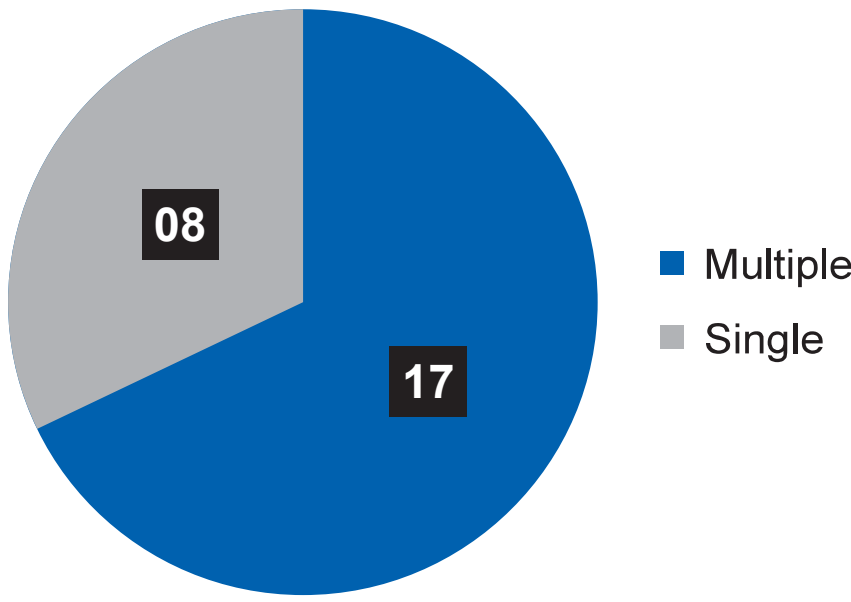

Figure 8: Chart showing single and multiple lesions in CT/MRI
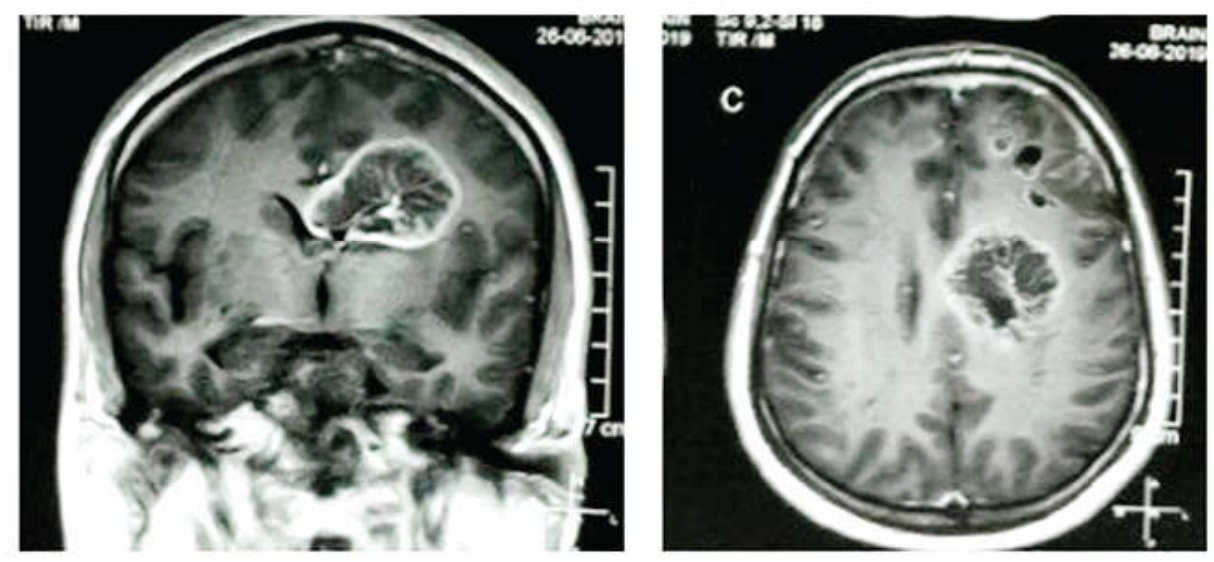

Figure 9: A case of glioblastoma
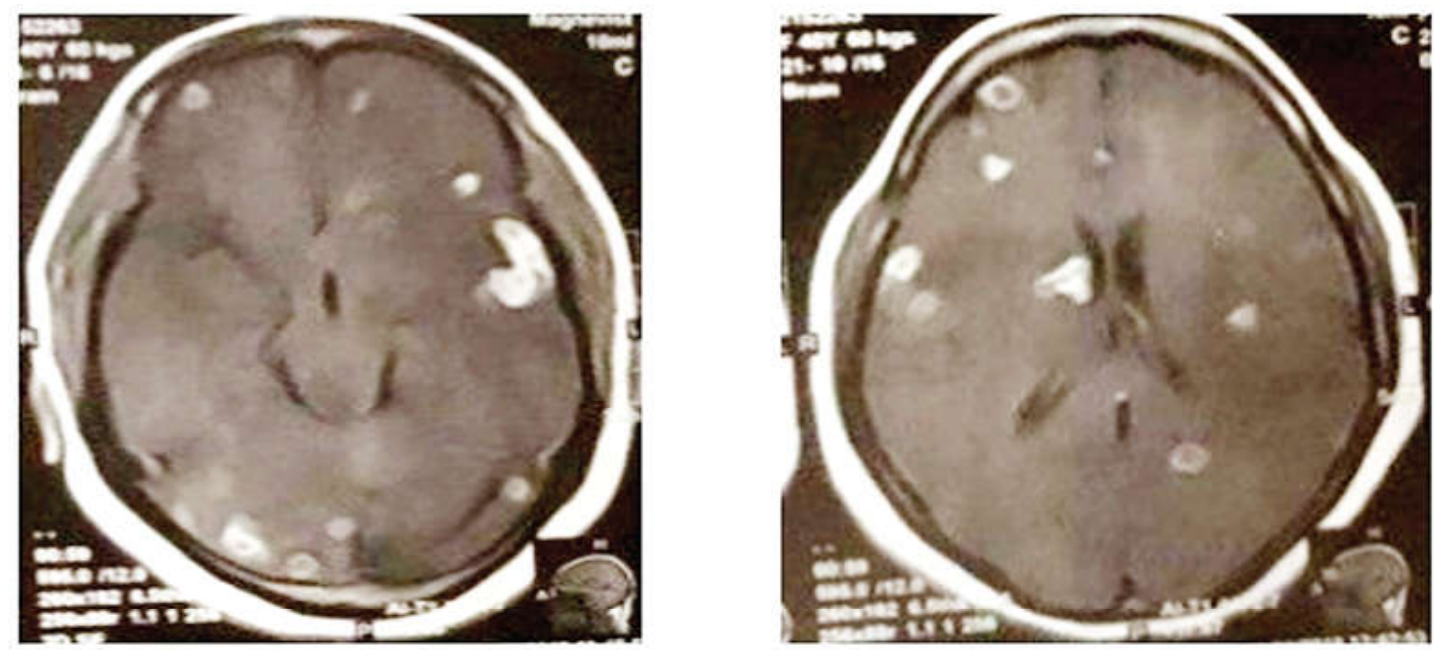

Fig 10: A case of Neurocysticercosis 

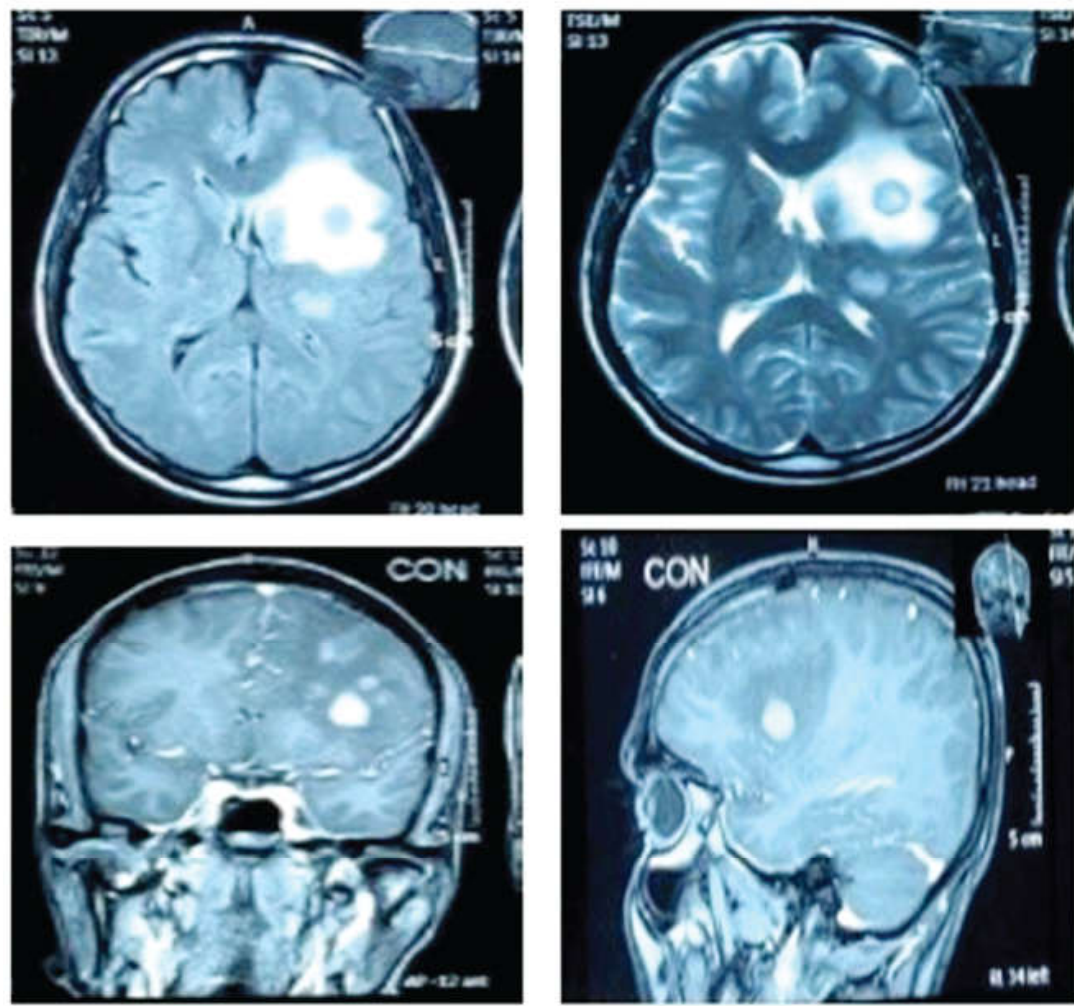

Figure 11: A Case of Non-Hodgkin's Lymphoma
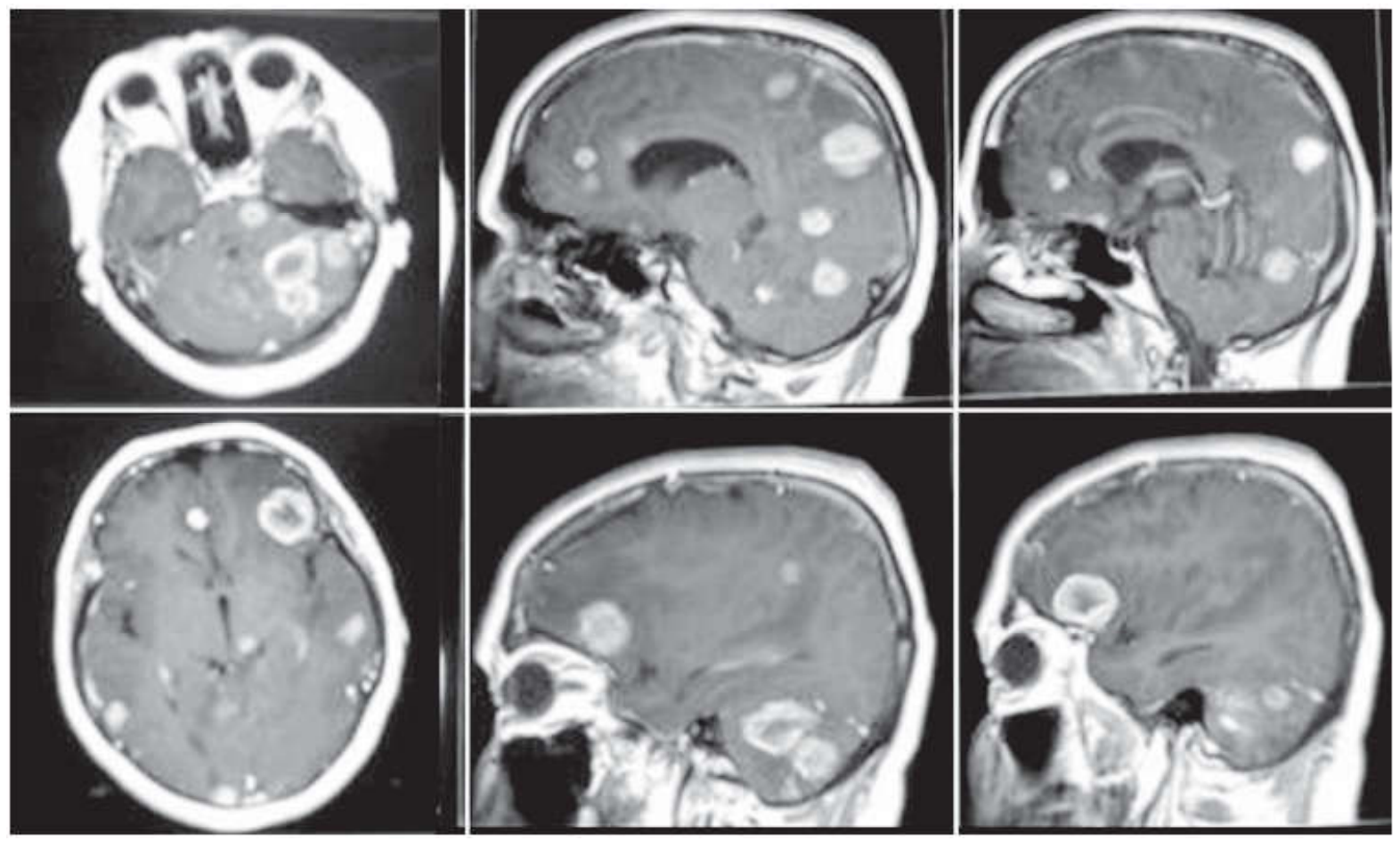

Figure 12: A Case of Metastatic Brain Tumor 

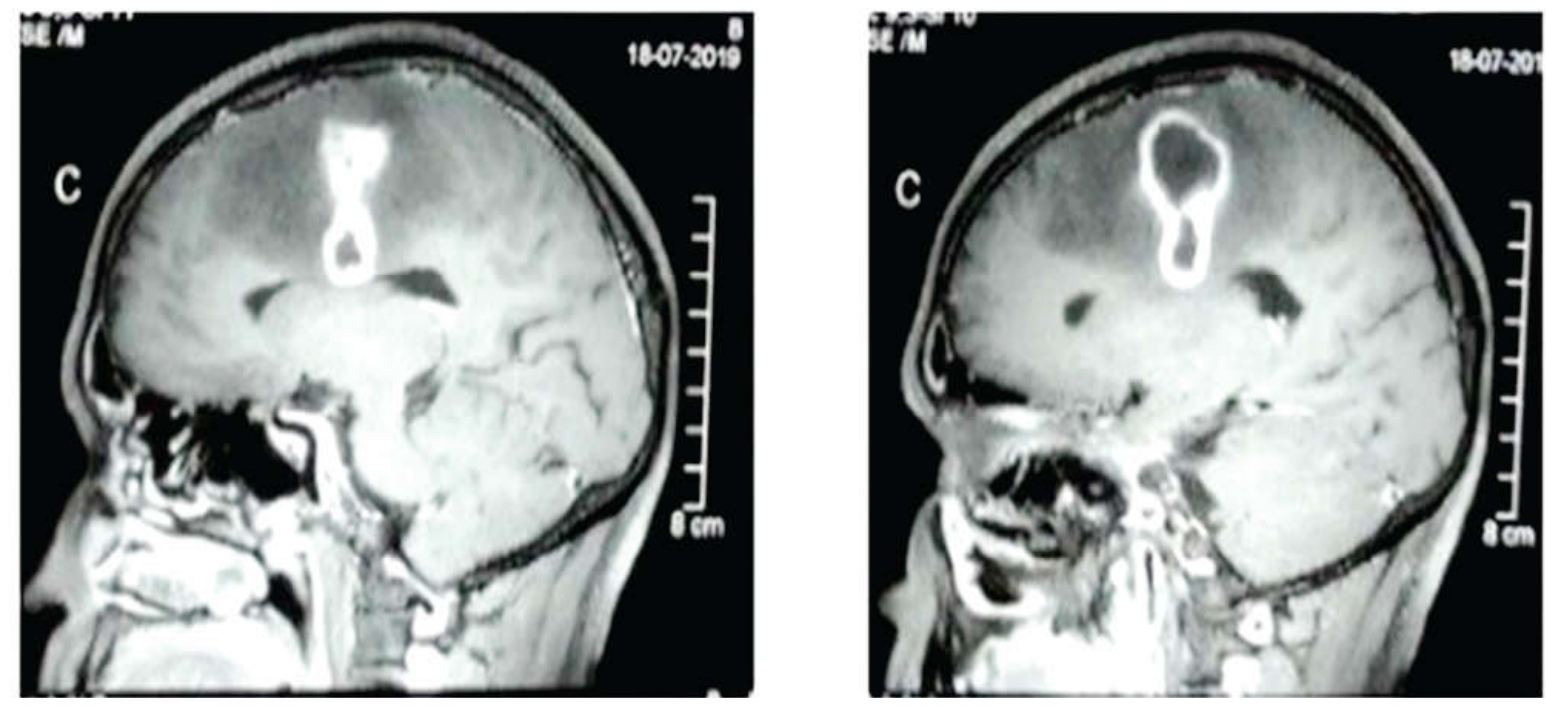

Fig 13: A Case of Brain Abscess

\section{Discussion:}

A vast range of diseases in this series of patients emphasize on the importance of lesion histology in order to avoid the risks of therapies based on the clinical and imaging data. Stereotactic biopsy with low morbidity and without mortality would fulfill this goal. In the analysis of Franzini et al., among 940 patients, $100(10.6 \%)$ of them had multiple lesions including 37\% malignant gliomas, $15 \%$ primary lymphoma, $15 \%$ brain metastases, $12 \%$ low grade gliomas, $10 \%$ infectious disease (including brain abscess and viral multifocal encephalitis) and 6\% ischemic lesions, and others had rare lesions ${ }^{17}$. In the study of Calisaneller et al., from 100 stereotactic biopsies, $4.25 \%$ of the cases were multiple ${ }^{13}$. In the analysis of Shahzadi et al., 7.6\% (22 of 288 cases) of thalamic lesion biopsies showed bilateral lesions, and in the study of Zali et al., 67\% of (n-90) cerebral lymphoma biopsies, revealed multiple lesions ${ }^{18,19}$.

In our setting the sample size was small only 25 among them 8 had single lesion (32\%) and 17 had multiple lesion (68\%) which is quite high percentage with other studies. Among them Glioblastoma multiforme $17 \%$, metastasis $17 \%$, tuberculosis
$5.88 \%$, pilocytic astrocytoma $11.76 \%$, Low grade glioma 5.88\%, abscess $11.76 \%$, Neurocysticercosis $5.88 \%$, Choroid plexus papilloma $5.88 \%$, gliosis in $17.3 \%$ respectively. We obtained postoperative CT scan of brain for every patient to see any complication like hematoma or significant edema. There was no significant complication found in any patient.

\section{Conclusion:}

Stereotactic surgery is a minimally invasive form of surgical intervention which makes use of a three-dimensional coordinate system to locate small targets inside the body and to perform on them some action such as ablation, biopsy, lesioning, injection, stimulation, implantation, radiosurgery (SRS), etc.

Stereotactic procedure is a safe, highly effective, preferred powerful tool in the diagnosis of benign, malignant and functional neurological disorders. With careful selection of patients and judicious use, we may use this procedure both in definitive diagnosis and treatment simultaneously. In future, this sort of minimally invasive technique may open new avenues of treatment in the fight against brain cancer. 


\section{TABLES}

Table 1: Presentation of Patients $(\mathrm{N}=25)$

\begin{tabular}{|c|c|}
\hline Presentation & Total \\
\hline Headache & 22 \\
\hline Vomiting & 18 \\
\hline Hemiparesis & 9 \\
\hline Visual problem & 15 \\
\hline
\end{tabular}

Table 2: Preoperative Diagnosis in CT/MRI $(\mathrm{N}=25)$

\begin{tabular}{|l|l|}
\hline Diagnosis & Number of patients $(\mathrm{N}=25)$ \\
\hline Glioblastoma multiforme & 5 \\
\hline Tuberculosis & 6 \\
\hline Metastasis & 5 \\
\hline Low grade glioma & 2 \\
\hline Abscess & 3 \\
\hline Pilocytic astrocytoma & 2 \\
\hline Neurocysticercosis & 2 \\
\hline
\end{tabular}

Table 3: Histopathological Diagnosis after Stereotactic Biopsy $(\mathrm{N}=25)$

\begin{tabular}{|l|l|l|l|}
\hline Histopathologic diagnosis & $\mathrm{N}=25$ & Single lesion & Multiple lesion \\
\hline Glioblastoma multiforme & 3 & 0 & 3 \\
\hline Metastasis & 3 & 0 & 3 \\
\hline Tuberculosis & 2 & 1 & 1 \\
\hline Low grade glioma-G-II & 2 & 1 & 1 \\
\hline Pilocytic astrocytoma & 3 & 1 & 2 \\
\hline Abscess & 2 & 0 & 2 \\
\hline Choroid plexus papilloma & 1 & 0 & 1 \\
\hline Malignant round cell tumor & 1 & 1 & 0 \\
\hline Non-Hodgkin lymphoma & 1 & 1 & 0 \\
\hline Neurocysticercosis & 1 & 0 & 1 \\
\hline Hematoma & 1 & 1 & 0 \\
\hline Gliosis & 5 & 2 & 3 \\
\hline Total & 25 & 8 & 17 \\
\hline
\end{tabular}




\section{References:}

1. Al- Rodhan NRF, Kelly PJ. Pioneers of stereotactic neurosurgery. Stereotact Funct Neurosurg 1992; 58: 60-66. https://doi.org/10.1159/000098974, PMid:1439351

2. Dittmar C. Ueber die Lage des soggenannten Gefaesszentrums in der Medulla oblongata. Ber saechsGesWiss Leipzig (Math phys) 1873, 25: 449-469.

3. Gildenberg PL. The history of stereotactic neurosurgery. Neurosurgery Clinics of North America 1990, Volume 1, Issue 4, Pages 765-780. https://doi.org/10.1016/S1042-3680(18)30772-1

4. Leksell, Lars. "Stereotactic radiosurgery". Journal of Neurology, Neurosurgery and Psychiatry 1983; 46 (9): 797-803. doi:10.1136/jnnp.46.9.797. PMC 1027560. https://doi.org/10.1136/jnnp.46.9.797, PMid:6352865 PMCid:PMC1027560

5. Solberg, Timothy D.; Siddon, Robert L.; Kavanagh, Brian. "Chapter 1: Historical Development of Stereotactic Ablative Radiotherapy". In Lo, Simon S.; Teh, B.S.; Lu, J.J.; Schefter, T.E. (eds.). Stereotactic body radiation therapy. Berlin: Springer 2012; pp. 9, 35. doi:10.1007/174_2012_540. ISBN 978-3-64225605-9., https://doi.org/10.1007/174_2012_540

6. Kirschner, M. "Die Punktionstechnik und die Elektrokoagulation des Ganglion Gasseri". Arch KlinChir 1933; 176: 581-620.

7. Kandel, Edward I. Functional and Stereotactic Neurosurgery. Boston, MA: Springer US 1989; p. 420. https://doi.org/10.1007/978-1-4613-0703-7

8. Uchimura Y. Narabayashi H. Stereo-encephalotomy. Psychiat Neurol. 1951; 52, 265-270.

9. Ohye CF. Odstad H. Forty years with Professor Narabayashi. Neurosugery 2004; 55, p 222-227. https://doi.org/10.1227/01.NEU.0000126954.53568.43, PMid:15214993

10. Narabayashi H. Okuma T. Shikiba S. Procaine oil blocking of the globus pallidus. AMA Arch NeurPsych 1956; 75(1), 36-48. https://doi.org/ 10.1001/archneurpsyc.1956.02330190052003, PMid:13275158
11. Austin G. Lee A. A plastic ball and socket type of stereotaxic detector. J Neurosurg 1958; 5, p264- 268. https://doi.org/10.3171/jns.1958.15.3.0264, PMid: 13539668

12. Gillingham, FJ. Small localised surgical lesions of the internal capsule in the treatment of the dyskinesias. Confin. Neurol. 1962; 22, 385-392. https://doi.org/ 10.1159/000104390, PMid:13947938

13. Horsley V. Clarke RH. The structure and functions of the cerebellum examined by a new method. Brain 1908; Vol-31 (1), p 45-124. https://doi.org/ $10.1093 /$ brain/31.1.45

14. Velasco Suarez MM. Escobedo FR. Stereotaxic intracerebral instillation of Dopa. Confin. Neurol. 1970; 32, 149-157. https://doi.org/10.1159/ 000103410, PMid:4926179

15. Wen DY, Hall WA, Miller DA, Seljeskog EL, Maxwell RE. Targeted brain biopsy: a comparison of freehand computed tomography-guided and stereotactic techniques. Neurosurgery, 1993; 32, 407-13. https://doi.org/10.1097/00006123-199303000-00011

16. Bernstein M, Parrent AG. Complications of CT-guided stereotactic biopsy of intra-axial brain lesions. J Neurosurg 1994; 81, 165-8. https://doi.org/ 10.3171/jns.1994.81.2.0165, PMid:8027795

17. Franzini A, Leocata F, Giorgi C, Allegranza A, Servello D, Broggi G. Role of stereotactic biopsy in multifocal brain lesions: Considerations on 100 consecutive cases. J Neurol Neurosurg Psychiatry 1994; 57, 95760. https://doi.org/10.1136/ jnnp.57.8.957, PMid:8057120 PMCid:PMC1073081

18. Shahzadi S, Andalibi R. Sharifi G. Biopsy of thalamic lesions using computed imaging assisted stereotaxis: Report of 15 years of experiences. Arch Iran Med $2005 ; 8,18891$.

19. Zali A. Shahzadi S. Mohammad Mohammadi A. Taherzadeh K. Parsa K. Cerebral lymphoma: Clinical and radiological findings in 90 cases. Arch Iran Med $2007 ; 10,1948$ 